\title{
Erratum to: One-Dimensional Structural Properties of Protein in the Coarse-Grained CABS Model
}

\section{Sebastian Kmiecik and Andrzej Kolinski}

\section{Erratum to:}

Chapter 8 in: Yaoqi Zhou et al. (eds.), Prediction of Protein

Secondary Structure, Methods in Molecular Biology, vol. 1484,

DOI 10.1007/978-1-4939-6406-2_21

The publisher regrets the error published in the print and online versions of this book. In the acknowledgements sections the grant has a typo. Corrections to chapter 8 , page 111 should be as follows.

Instead of

"MAESTRO 2014/14/A/ST6/0008"

The grant number should be

“MAESTRO 2014/14/A/ST6/00088" 